\title{
Critical Eclecticism. The way(s) of the Porto School.
}

\author{
Eduardo Fernandes
}

The term "Porto School" designates more than just a School of Architecture; it implies an identity that relates the pedagogy of a teaching institution with the ideas and the architectural practice of its professors and / or former students, resulting of the transmission (and update) of a way of thinking connected to a way of doing.

Throughout the history of the School, the basis for the transmissibility of this identity was the official teaching of architecture in Porto (first in the School of Fine Arts, after 1984 in the Faculty of Architecture); but it also occurred in the studios of the architects (teachers and/or former students), where common principles of thought, method and taste were shared with the young disciples. The educational system of the School of Porto is thus complemented by the practice of the studios, where the small scale allows the proximity between master and apprentice. There are similarities between the work methods in the School (where the Studio classes simulate the work of an office, in a process called school-atelier) and in the studios (where the same kind of approach is more realistical, because it takes place in a professional environment); so, the ateliers of the Porto architects are an unofficial complement of the pedagogy of the School: successive generations of students / employees, will become teachers / chief-architects, influencing new generations with their experience.

\section{Genesis}

The origins of this identity can be related to the work of Fernando Távora, as a theoretician, an architect and a professor; but it would be incorrect not to mention two of the antecedents that contribute to the emergence of these ideas: Marques da Silva and Carlos Ramos.

We must go back to the time when the presence of Marques da Silva ${ }^{1}$ dominated the teaching of the School of Fine Arts of Porto (EBAP) to find the source of some of the features that still exist in the present teaching of the School: the accuracy in the drawings, the importance given to the function and to the construction in the design options, the eclectic use of different languages and the practice of the school-atelier (Cardoso, 1997).

Later, we can find a very important contribute in the pedagogy of Carlos Ramos, ${ }^{2}$ who achieves a clear modernization of the teaching of EBAP, introducing new methods (influenced by the pedagogy of the Bauhaus) and surpassing the remaining anachronistic features of the "Beaux-Arts" legacy (Filgueiras, 1986). However, if we can find in the ideas of Carlos Ramos the will to seek a Modern Portuguese Architecture, he was not able to clearly point out the way, neither in his writing nor in his architecture.

Thus, the birth of the Porto School is mainly related to Fernando Távora. In his text "The Problem of the Portuguese House" (Távora, 1945) we can find the three principles that will support this identity: learning from the past, thinking about the present and projecting the future, combining the specificity of each site and of each context with the modernity of the coeval foreign architecture. This attitude (considering context, history and modernity as major references) is the genesis of what we can call "the Architecture of Porto" and the basis that underlies this School.

This text marks the beginning of a theoretical construct that Távora formulates from 1945 to 1955. In the beginning of his long teaching career in EBAP (from 1951 to 1993), he laid the seeds for the genesis of a School and found fertile ground in the period between 1955 and 1961, when several events of major importance for the recognition and consolidation of these ideas occurred: in 1955 the field work of the "Surveys on Portuguese Vernacular Architecture" begins and Álvaro Siza starts his collaboration in Fernando Távora's office; in the following year, a delegation of Porto architects participates in the CIAM X; in 1957 an important Reform of the teaching of the Fine Arts begins to be applied in Portuguese Schools; in the next year Siza leaves Távora's studio and starts working in his own office; in 1960, Nuno Portas starts to disclose the work of these two architects in the magazine Architecture; finally, in 1961, the book that summarizes the results of the "Surveys" is published (SNA, 1961). Also in this period, we should notice

\footnotetext{
${ }^{1}$ Marques da Silva was Professor of Architecture since 1907 and the Director of the School after 1913.

2 Carlos Ramos was Professor of Architecture since 1940 and the Director of the School from 1952 to 1969.
} 
the beginning and / or conclusion of some important projects: the Municipal Market of Vila da Feira, the house of Ofir, the tennis pavilion in Quinta da Conceição and the school of Cedro (Távora), the Tea House in Leça da Palmeira and the swimming pool in Quinta da Conceição (Siza). ${ }^{3}$ The signs of the genesis of a Modern Portuguese Architecture appear in all these buildings, where we can recognize the full realization of the intentions expressed in Távora's theoretical work: their modernity is expressed in the quality and accuracy of the relationships they create with life, in a seamless integration of all elements (Távora, 1952).

\section{Common Grounds.}

The teaching of Architecture in Porto was always based on a Vitruvian understanding of the role of the architect, considered to be an expert on general knowledge (a technician/artist who knows how to relate with other technicians and artists). This concept implies an idea of comprehensive (but not specialized) education of the architect, in the belief that he is the single professional that, by the scope of his training, can synthesize all the different disciplines converging in architectural work. But implicit in Távora's approach there was a new disciplinary attitude: he believed that the architect should learn to put his efforts in the service of the collective, assuming architecture as a result of a collaboration between all the individuals involved in the planning, design, construction and use of buildings and spaces. This concept of collaboration was intended in two categories: horizontal, manifested among men of the same time, and vertical, which takes place between men of successive times, because the culture of the present should manifest the legacy of the past (Távora, 1953).

The teachers / architects of the Porto School also share a common understanding of the role of manual drawing as a primary method of conception and synthesis in the process of design. In the most interesting examples of their architecture we recognize the use of this instrument to combine different models and languages in a compound that aggregates responses to multiple factors (Távora, 1957), relating the building with the site in an exercise of figurative art organized along a promenade architecturelle. ${ }^{4}$

Therefore, the School of Porto is a theoretical construct, the result of a long journey through a winding road, guided by a set of conscious choices, in which the consciousness of the discarded paths is as important as the choice of the way(s). However, beyond the evidence of this common ground, the theoretical identities of the School (like its architectural expression) do not present themselves as a coherent whole, with a linear sequence and a unitary language. They never did: their higher quality lies, precisely, in the richness of its evolutionary process, built around some (few) consensus and diverging on everything else.

\section{To be or not to be}

Throughout the XXth century, the teaching of architecture in Porto lived in a permanent state of convulsion. The departure of the Marques da Silva (in the end of the thirties) and Carlos Ramos (in the end of the sixties) caused the emergence of two important identity crises and (in the nineties) the retirement of Fernando Távora triggered a similar feeling of emptiness. Before and after the Portuguese Revolution of 1974, the social and political involvement of teachers and students almost paralyzed the School. In the late seventies and the early eighties, the process of transition from the Fine Arts School to the University implied great internal debate and some difficult pedagogic battles. Finally, along all this years, the implementation of the school-atelier paradigm had to face successive difficulties in achieving a good teacher / student ratio. Yet, throughout the history of the School, it seems clear that the transmissibility of the ideas and methods that we can relate to its identity has been achieved, despite the successive crises and problems.

However, the ideas of the Porto School were more cohesive and coherent, as a response to the Portuguese context, when this background inspired clear reactions. At the end of the $80 \mathrm{~s}$, Porto architects cease to be motivated by the response to a hostile context (the ancient fascist regime) or a dramatic situation (the needs of the populations in the SAAL Program); we can even speak of a growth crisis, triggered by the growing international impact of the work of Álvaro Siza. Facing this new and friendly context, the School loses coherence and internal cohesion; the interrelated critical discourses of Nuno Portas, Álvaro Siza, Manuel Mendes, Alves Costa and Jorge Figueira represent a reaction to this new condition, less clear, more diffuse and dominated by the appearance of a stereotypical idea of the architecture of the School (a Porto Style).

This new internal criticism leads to the generalization of a negative discourse, that proclaims that the term School of Porto designated an entity that no longer exists (namely, that Porto has a Faculty of Architecture, but not a School with a shared Identity). This is the result of a change of scale: the School, seen as the result of the transmission mechanisms of a way of thinking connected to a way of doing, is now expanded into a complex network of mutual influences of many architects and materialized through a great number of buildings, texts and images. The list of masters is no longer limited to the inevitable names of Fernando Távora, Álvaro Siza and (more recently) Eduardo Souto Moura: it includes many other architects or critics with published work.

This implies that there isn't a consensus around an idea of School: there are many theoretical and practical interpretations of its ways. However, we can find new common principles in the writings of Alves Costa and in the work of Álvaro Siza (in the 80s), allowing the update of the identity of the School in a new interpretation that is justified by the history of Portuguese architecture, highlighting the

\footnotetext{
${ }^{3}$ See illustrations 1 to 6.

4 Promenade architecturelle is a concept theorized and applied by Le Corbusier and implies that buildings can be perceived as a sequence of forms and spaces in a path ordered, controlled and paced by the architect.
} 
miscegenation processes that characterize its specificity. It explains why the languages of the Porto School can differ, according to the intentional choice of external influences, deliberately used in a process of critical eclecticism, ${ }^{5}$ considering the intentional relations between context, scale, function, image and meaning.

\section{Porto Style or Porto School?}

Today, we continue to recognize in the work of the School of Porto the results of the transmission of a way of thinking related to a way of doing, connecting a concern with social responsibility (perceived through the notions of collaboration and relationship with the context) with a timeless concept of modernity, the belief that architecture should be considered figurative art (perceived in the pace of a promenade thoroughly controlled in time and space), a Vitruvian understanding of the education of the architects, the practice of manual drawing as a primary method of conception and the requirement of accuracy in the processes of work and communication. Although we can find in the different approaches of Álvaro Siza and Souto Moura ${ }^{6}$ the same principles of this current identity of the School of Porto (sharing the legacy of Fernando Távora as a common ground), there is an increasing variety of interpretations that the multiple agents of the School can do, following the same concepts.

Throughout the long history of the School, two phenomena seem to coexist. The first is an uncritical reuse of formal references, reproduced from published images of the work of the main architects of Porto, which establishes what we can call a Porto Style: a tendency to perpetuate the repetition of images without understanding the processes that generated them. It is the awareness of the existence of this Porto Style that justifies the various statements on the death of the Porto School that we can find, since the 90s, in most of the discourses on the subject.

But we can also find recent examples of the transmissibility of the identity of the School; they imply the consideration of the theoretic values of each external reference and its conscientious use, facing a given context and program, in an attitude that may be more or less critical of these circumstances. In this case, the ways of Porto are understood and can be updated by the new generations of architects, working with new references of the present international architectural context (exponentially more complex, profuse and accessible) and with new national values, allowing the appearance of languages and shapes that are (apparently) distant of what is usually called the language of the Porto School.

In the globalized world in which we now live, the habit of miscegenation and the meeting of cultures as a condition can no longer be considered a Portuguese specificity. But the cultural heritage of the School of Porto can still present an important set of lessons on how to consciously undertake these mixing processes. Therefore, the full transmissibility of the ways of the School implies an equidistant position between the respect for this inherited principles and the will to update them. After all, it was this process of evolution that allowed the survival of this identity, from 1945 to the present day.

Today, as always, the relationship between architectural practice, theory and education is crucial: to survive the trivialization of the formal models it creates, the School of Porto needs a permanently renewed theoretical construct, adapting its pedagogy to the information society and maintaining the vitality of the methods of transmission of its way(s).

\section{References:}

António Cardoso, O Arquitecto José Marques da Silva e a arquitectura no Norte do país na primeira metade do século XX, Porto, FAUP, 1997.

Eduardo Fernandes, The Choice of Oporto: contributions to update the idea of a School, Ph.D., Guimarães, School of Architecture of the University of Minho, 2011.

Oliveira Lixa Filgueiras, "A Escola do Porto (1940/69)", Carlos Ramos, exposição retrospectiva da sua obra, Lisboa, Fundação Calouste Gulbenkian, 1986.

Kenneth Frampton, Modern Architecture: a Critical History, London, Thames and Hudson, 1985 (1st ed.: 1980).

SNA, Arquitectura Popular em Portugal, Lisboa, Sindicato Nacional dos Arquitectos, 1961.

Fernando Távora, "O Problema da Casa Portuguesa", ALĖO, Lisbon, November 10 1945, 10.

Fernando Távora, "O Porto e a Arquitectura Moderna", revista Panorama n 4, 1952.

Fernando Távora, "Da Colaboração em Arquitectura e Urbanismo", Comércio do Porto, March 24 1953, 5.

Fernando Távora, "Casa em Ofir", Arquitectura n. 59, Lisbon, July 1957.

Vitruvius (2006). 'De Architetura Libri Decem' (1st. Century a. C.). Lisbon: IST Press.

\footnotetext{
${ }^{5}$ Critical eclecticism (Fernandes, 2011) is an expression that we consider more appropriate to designate the architecture of the Porto School than the former denomination Critical Regionalism (Frampton, 1985), which was very accurate to describe the work of Siza in the 60's and early 70's, but is no longer valid from the 80's to the present day.

${ }^{6}$ See illustrations 7 and 8.
} 


\section{Abstract}

The term "Porto School" designates an identity that relates the pedagogy of a teaching institution with the ideas and the architectural practice of its professors and / or former students, resulting of the transmission (and update) of a way of thinking connected to a way of doing: a concern with social responsibility (perceived through the notions of collaboration and relationship with the context), a timeless concept of modernity, an intentional appropriation and miscegenation of models (in a process that we can call critical eclecticism), the belief that architecture should be considered figurative art (perceived in the pace of a promenade thoroughly controlled in time and space), a Vitruvian understanding of the education of the architects, the practice of manual drawing as a primary method of conception and the requirement of accuracy in the processes of work and communication.

\section{Short biography}

Eduardo Fernandes (1966, Porto).

Architect (1992, Faculty of Architecture, Porto University).

Master in Planning of the Urban Environment (1998, Faculties of Architecture and Engineering, Porto University).

Assistant Professor (and Course Director) of the Master in Architecture of Minho University, Portugal.

Author of several architectural projects and published texts.

\section{Captions and credits of the illustrations}

Illustration 1: Municipal Market of Vila da Feira, Fernando Távora, 1953-59 (photo: Eduardo Fernandes).

Illustration 2: Holiday House in Ofir, Fernando Távora, 1957-58 (photo: Eduardo Fernandes).

Illustration 3: Tennis Pavilion of Quinta da Conceição, Leça da Palmeira, Fernando Távora, 1956-60 (photo: Eduardo Fernandes).

Illustration 4: Cedro Primary School, Gaia, Fernando Távora, 1954-59 (photo: Eduardo Fernandes).

Illustration 5: Tea House in Leça da Palmeira, Álvaro Siza, 1958-63 (photo: Eduardo Fernandes).

Illustration 6: Swimming Pool of Quinta da Conceição in Leça da Palmeira, Álvaro Siza, 1958-65 (photo: Eduardo Fernandes).

Illustration 7: Faculty of Architecture, Porto, Álvaro Siza, 1986-96 (photo: Eduardo Fernandes).

Illustration 8: AXA Stadium, Braga, Eduardo Souto Moura, 2004 (photo: Eduardo Fernandes). 


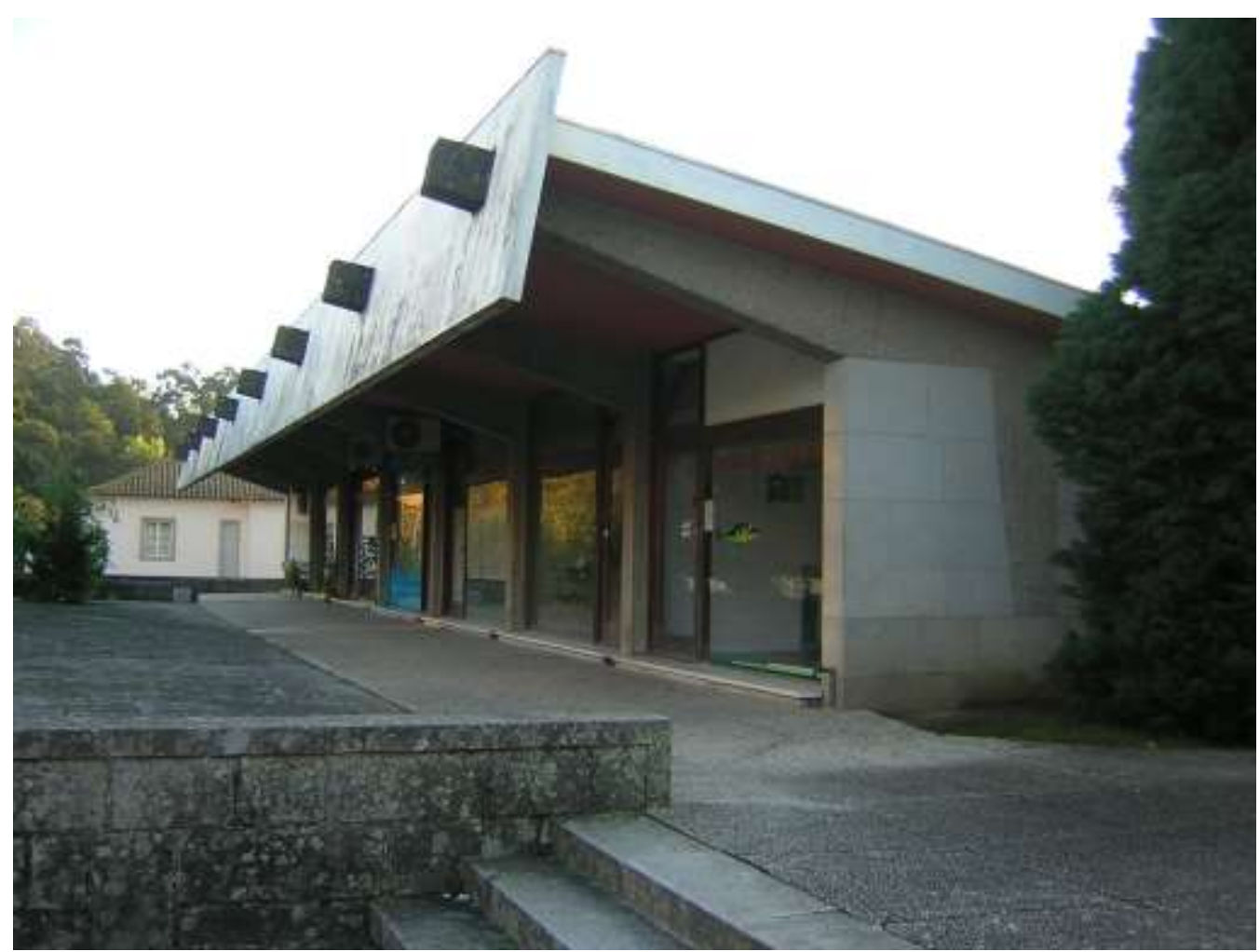

Illustration 1: Municipal Market of Vila da Feira, Fernando Távora, 1953-59 (photo: Eduardo Fernandes). 


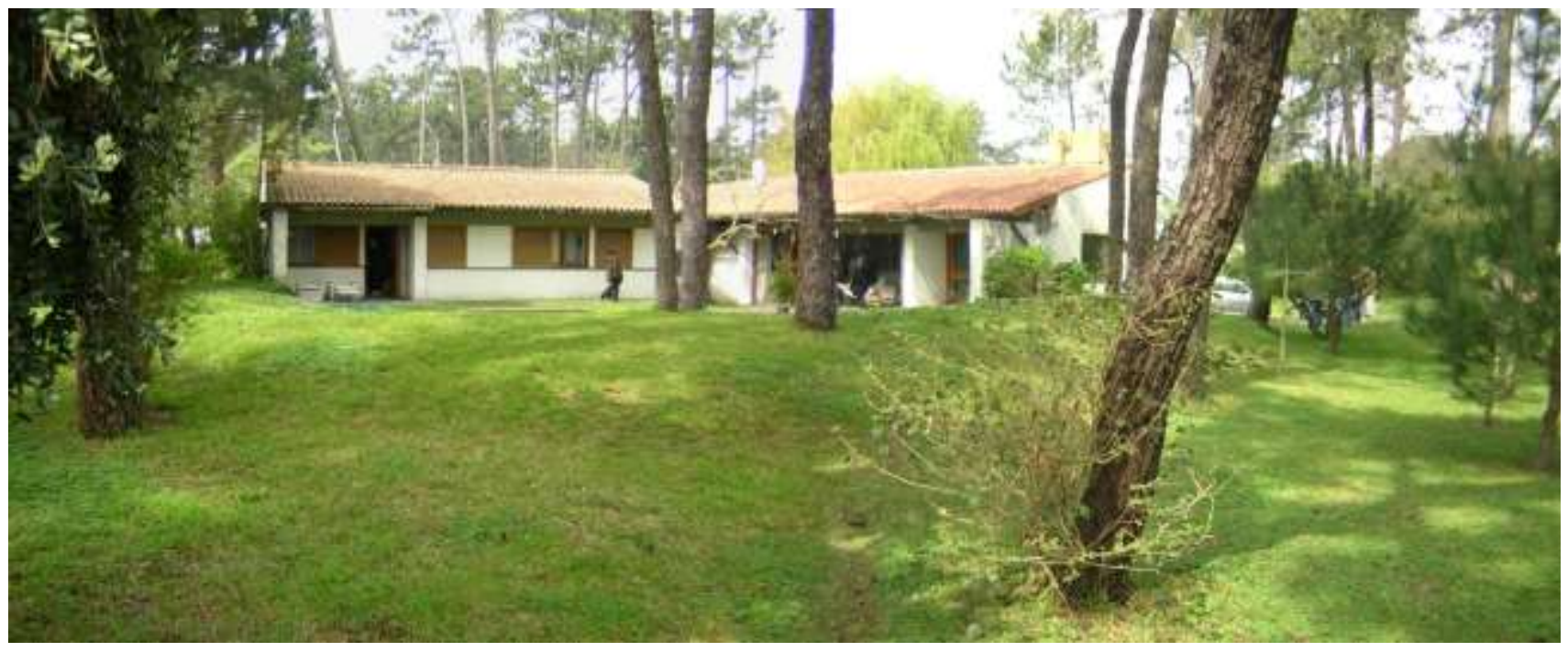

Illustration 2: Holiday House in Ofir, Fernando Távora, 1957-58 (photo: Eduardo Fernandes). 


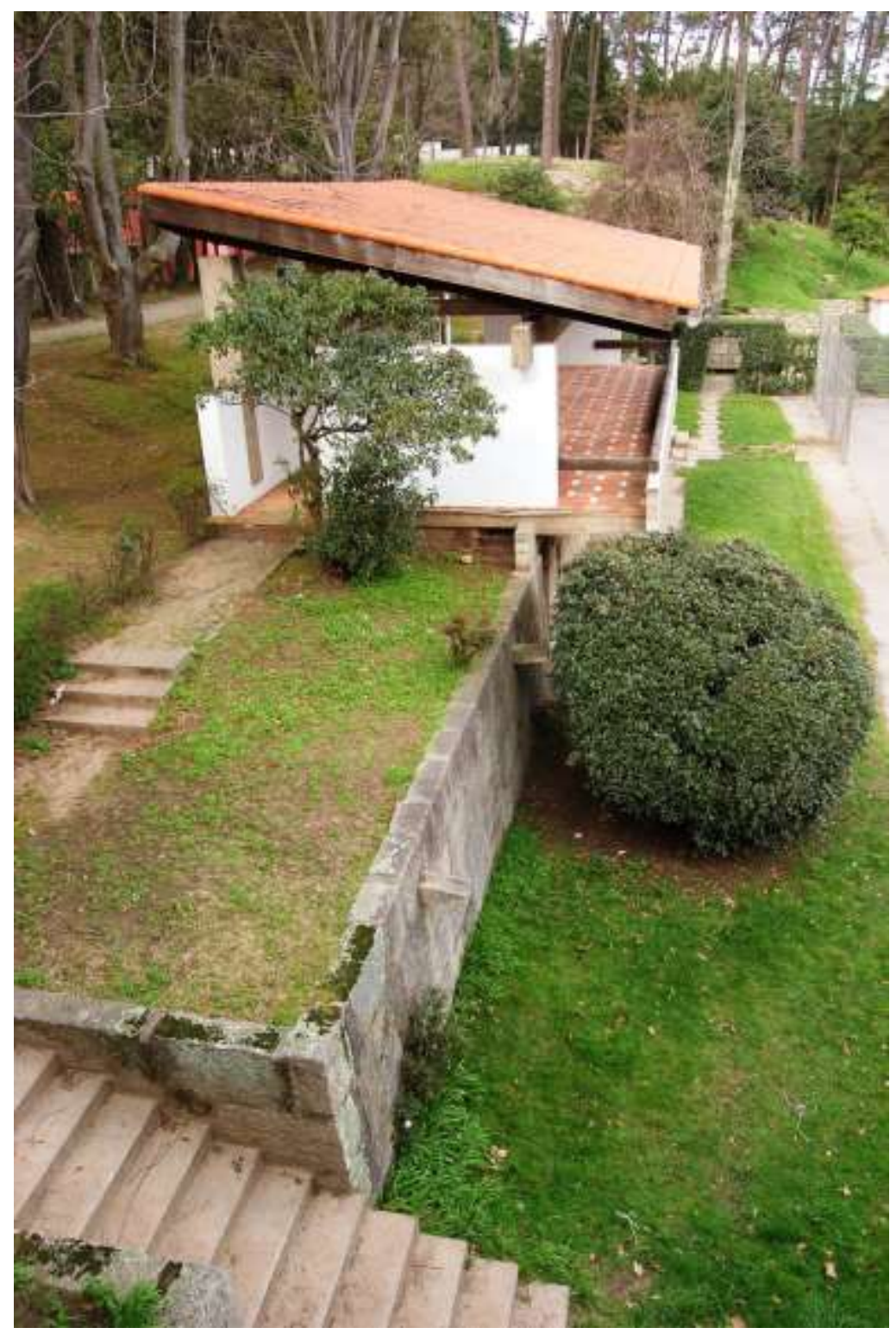

Illustration 3: Tennis Pavilion of Quinta da Conceição, Leça da Palmeira, Fernando Távora, 1956-60 (photo: Eduardo Fernandes). 


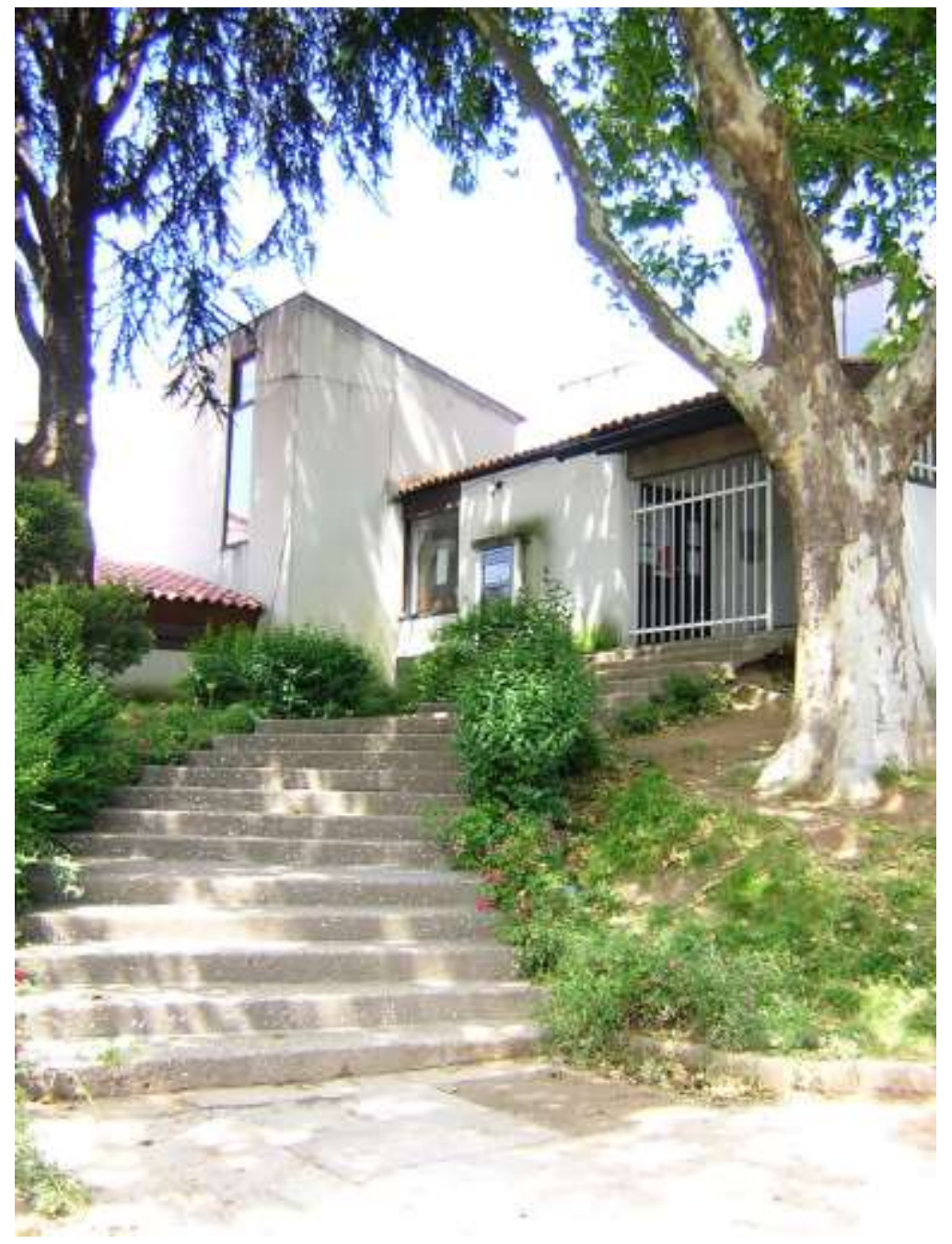

Illustration 4: Cedro Primary School, Gaia, Fernando Távora, 1954-59 (photo: Eduardo Fernandes). 


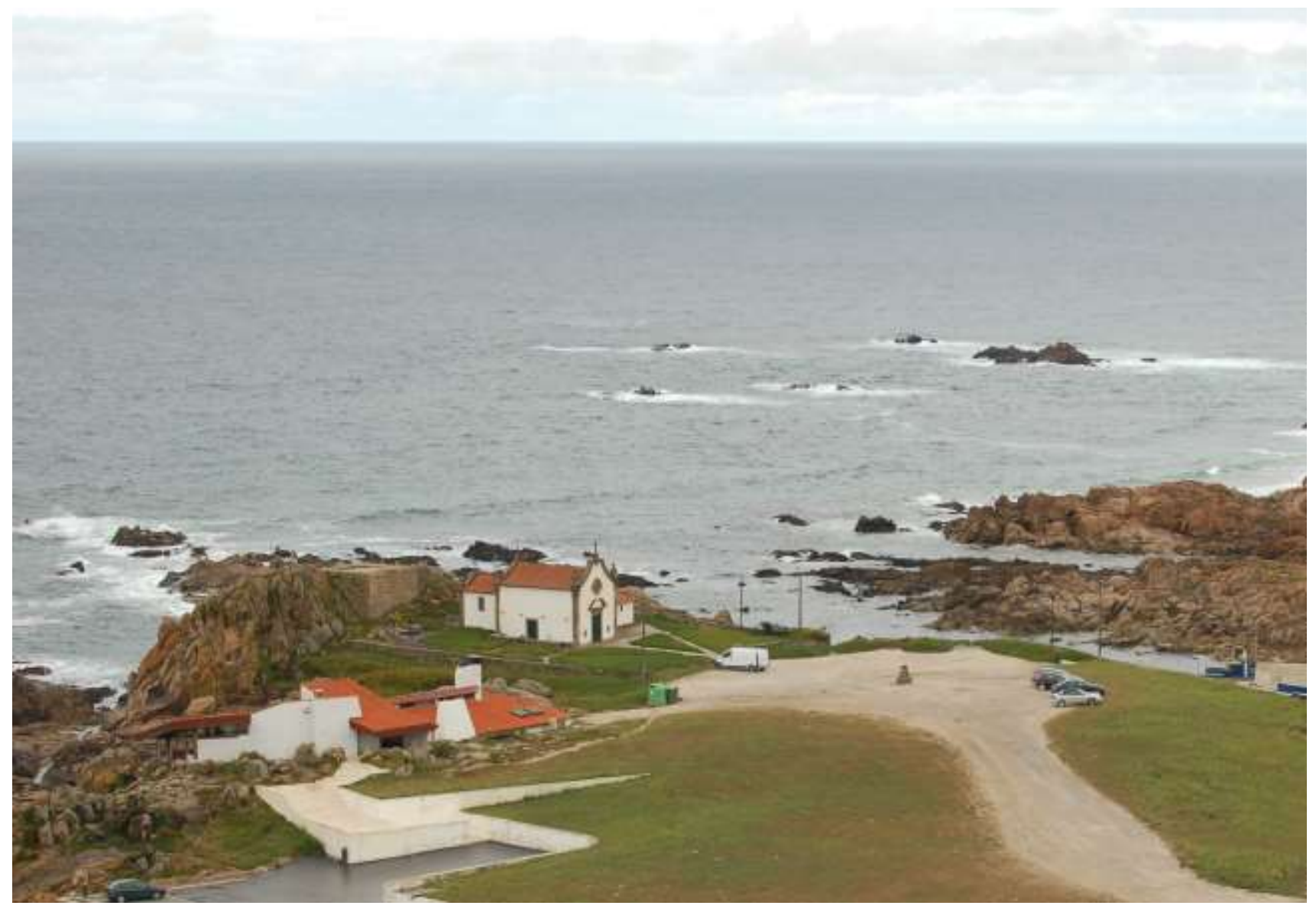

Illustration 5: Tea House in Leça da Palmeira, Álvaro Siza, 1958-63 (photo: Eduardo Fernandes). 


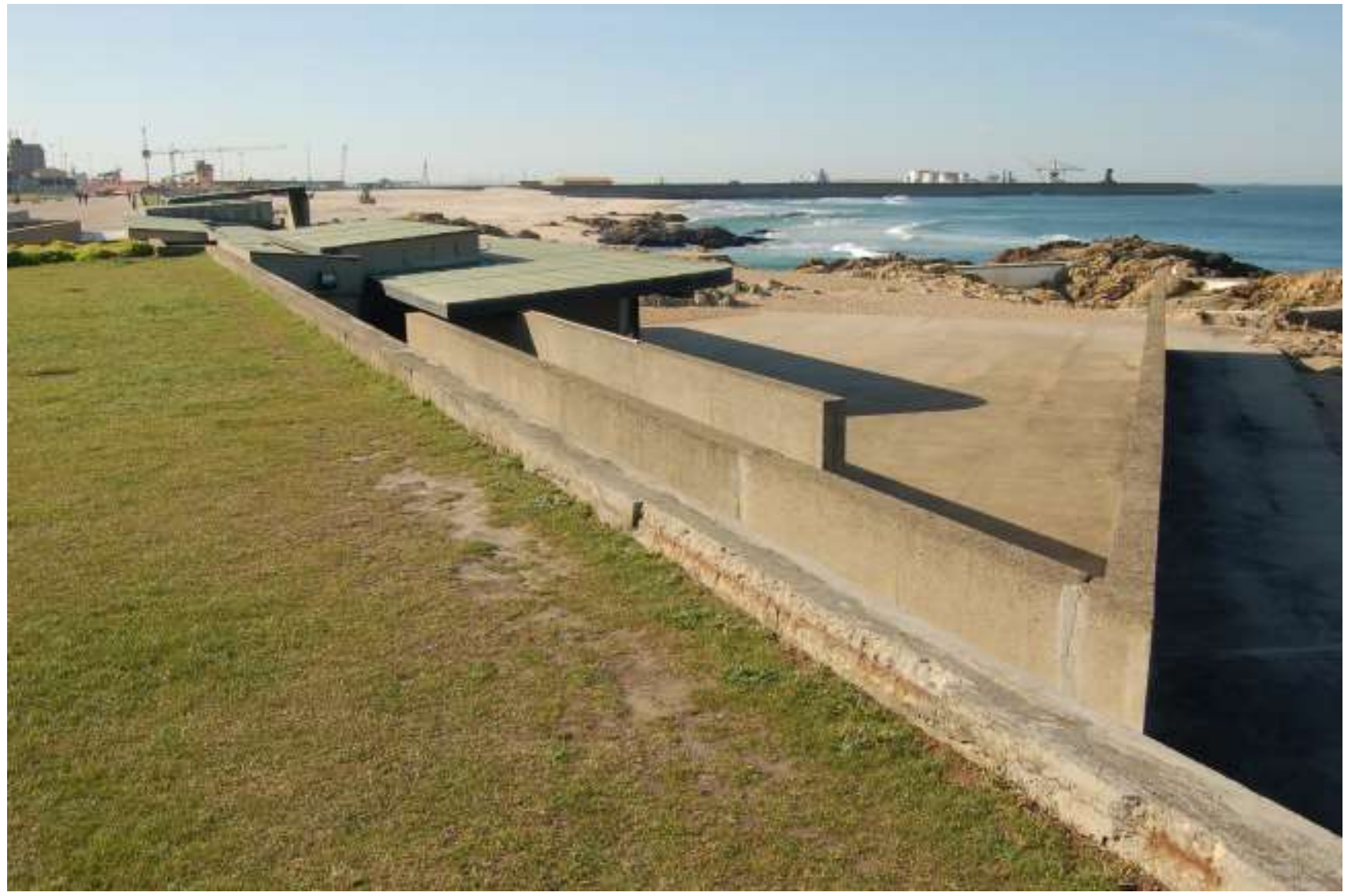

Illustration 6: Swimming Pool of Quinta da Conceição in Leça da Palmeira, Álvaro Siza, 1958-65 (photo: Eduardo Fernandes). 


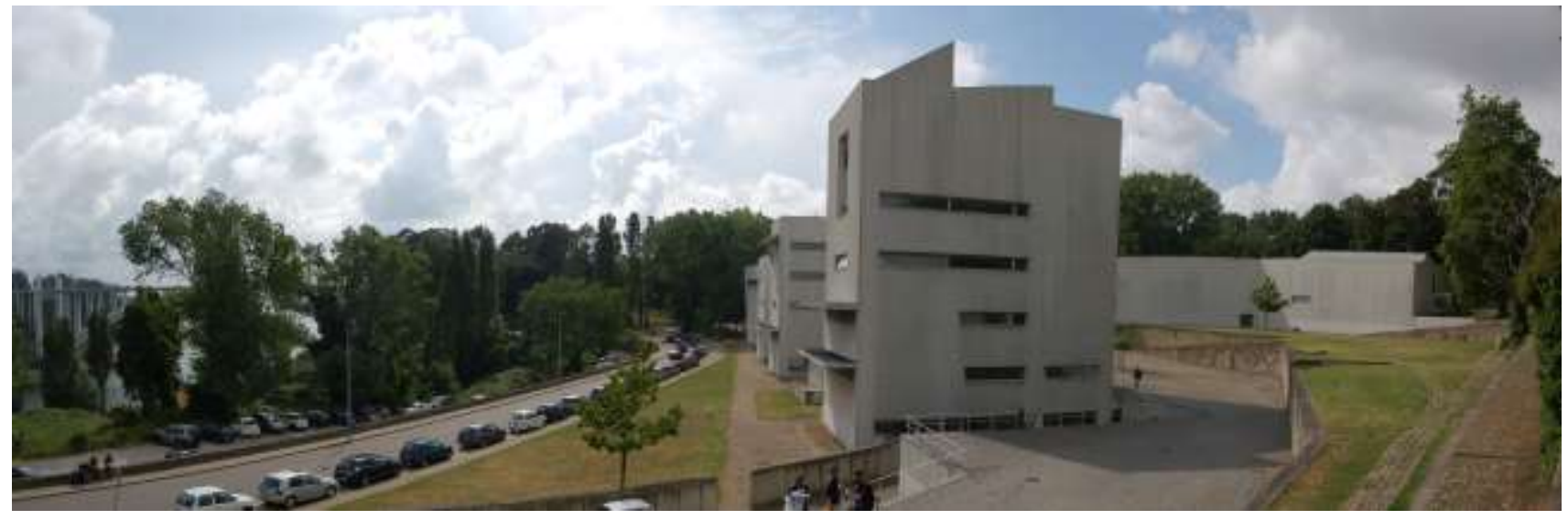

Illustration 7: Faculty of Architecture, Porto, Álvaro Siza, 1986-96 (photo: Eduardo Fernandes). 


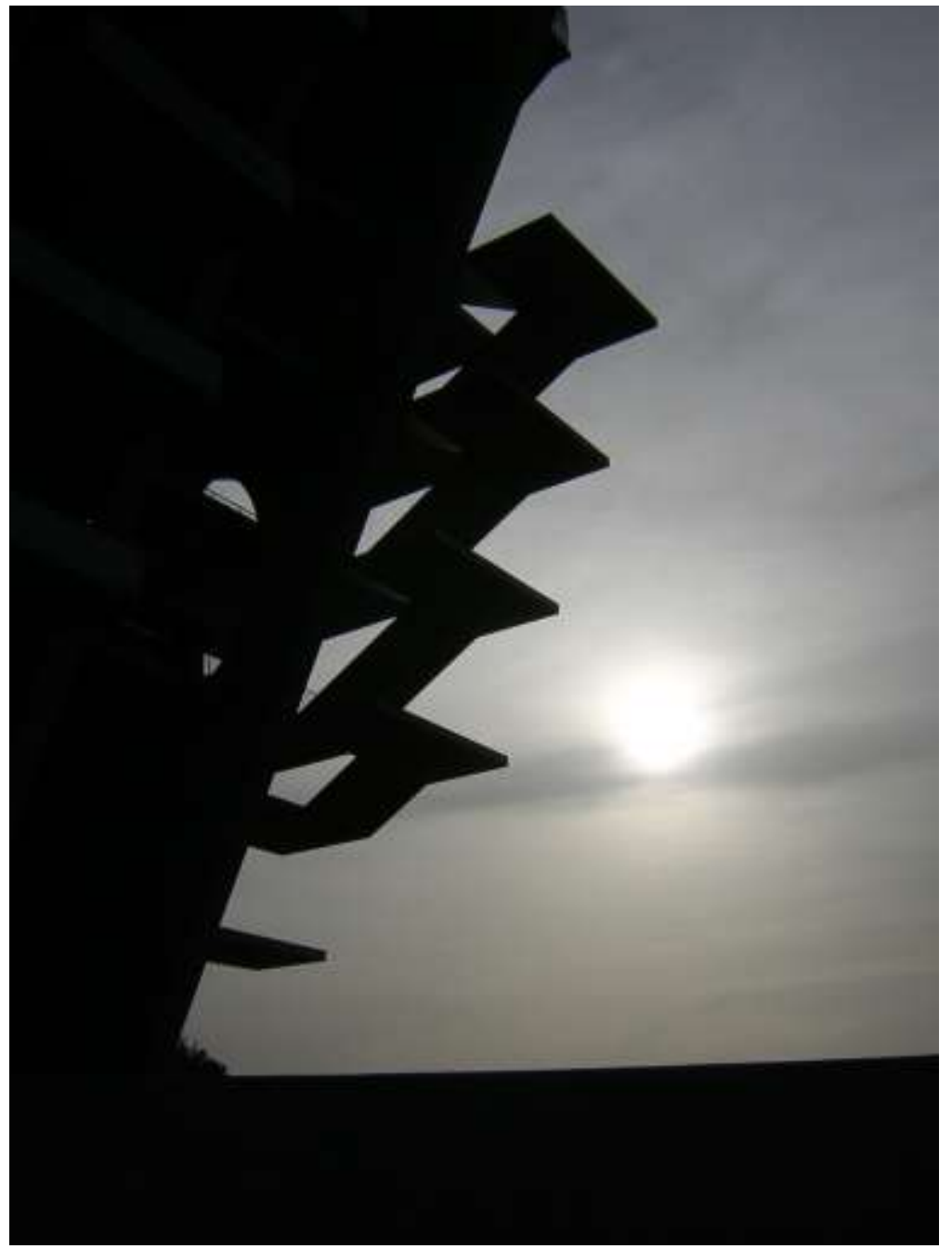

Illustration 8: AXA Stadium, Braga, Eduardo Souto Moura, 2004 (photo: Eduardo Fernandes). 